\title{
Coaching for wisdom: System 3 thinking in complex decision making
}

\author{
Peter J. Webb
}

Intentional Training Concepts Pty Ltd

Melbourne, Australia

\begin{abstract}
Wisdom is generally considered to be a religious, philosophical, social, and cultural concept, but it figures prominently in positive psychology as an important constituent of a meaningful life. Wise decision making is key to creating a better world because it involves using intelligence, creativity, and knowledge for common good (Sternberg, 2019a). The idea of bringing coaching to cultivate wise decision making is a way to improve the odds that individual leaders will think, feel, and act wisely knowing that the products of their decisions must be good for society as well as for the company (Kilburg, 2006). This paper proposes a third system of thinking arising from new research in the psychology of wisdom and highlights evidence-based interventions which coaches can apply to promote wise decision making in their clients, advocating for a practice of coaching for wisdom.
\end{abstract}

Keywords: wisdom, psychology, leadership, decision making, coaching

\section{Introduction}

According to Kilburg (2000; 2006), when coaching is done well, it should deliberately promote wisdom in clients, particularly when applied to leaders of private enterprise, government, community, and political organisations whose decisions impact the global community. The practice of coaching for wisdom is underpinned by a literature in psychology that stretches back to the 1980s and has helped shape not only the domain of wisdom but also its products, such as wise reasoning and wise actions. This has given rise to empirical findings that lend themselves to practical, evidence-based applications by coaches seeking to enhance wisdom-related performance in their clients (including wise decision making).

Wisdom is a broad topic embedded within religious, mystical, and philosophical traditions over millennia. This paper deliberately focuses on those psychological determinants of wisdom that may be applied to the effective 
coaching of leaders at complex decision points, where doubt, dilemma, or disruption abound. Wise decision-making is informed by the idea that information relevant to a decision is processed through two primary styles of thinking; fast and intuitive (System 1), and slow and logical (System 2). While both systems are relevant to solving particular kinds of problems, this paper proposes a third system of thinking which arises out of a consideration of the neurobiological correlates of wisdom. System 3 thinking is activated when leaders encounter novel circumstances, which demand consideration be given to the (short and long term) moral, social and environmental consequences. Here the challenge is making decisions for the common good, even if that means making the least worst choice. In addition to defining what is meant by System 3 thinking, this paper will describe its six dimensions, which coaches can utilize to engage clients in thinking and acting more wisely. These dimensions include: focus, life experience, decisiveness, compassion, emotional regulation, and tolerance for divergent values.

\section{The Psychology of Wisdom}

The psychological study of wisdom has been conducted along five distinct lines of enquiry. These include wisdom as being related to (i) character, (ii) expertise, (iii) balance, and (iv) reasoning, along with (iv) neurobiological investigations of the construct.

\section{Wisdom as Character}

The concept of wisdom is inevitably based on the perception of the personal and behavioural characteristics exhibited by people considered to be wise. Ardelt $(2003,2004)$ defines wisdom as a personality in which cognitive, reflective, and affective traits are integrated. Similarly, Birren and Fisher (1990) consider wisdom to be an integration of cognitive, affective, and conative features of human abilities. A wise person is assumed to possess such positive qualities as maturity, an integrated personality, and superior judgment skills (Ardelt, 2004; Baltes \& Smith, 1990). Character-oriented conceptualizations of wisdom form the basis of describing what it means to be a wise leader (McKenna et al., 2006; Nonaka \& Takeuchi, 2011). For example, Intezari and Puleen (2019) define wisdom in the business context as "the professional manager's capacity to critically and accurately assess self, others, and the decision situation, and to integrate personal and communal knowledge and values into decisions and actions in order to achieve the well-being of all involved, over both the short and long term" (p. 56). 


\section{Wisdom as Expertise}

The Berlin Wisdom Paradigm (BWP) established wisdom-related performance as a scientifically grounded psychological construct defined as "good judgement and advice in difficult and uncertain matters of life" (Baltes \& Staudinger, 2000). The five criteria used to assess wisdom-related performance in individuals under various experimental conditions are: (i) rich factual knowledge about human nature and the life course; (ii) rich procedural knowledge about ways of dealing with life problems; (iii) lifespan contextualism (an awareness and understanding of the many contexts of life, how they relate to each other, and how they change over the lifespan); (iv) value relativism and tolerance (an acknowledgement of individual, social, and cultural differences in values and life priorities), and (v) knowledge about handling uncertainty, including the limits of one's own knowledge (Kunzmann \& Baltes, 2005).

The BWP's conceptualization of wisdom as a state-based approach supports the idea that appropriately trained coaches could enhance wise reasoning and wise decision-making in their clients. As outlined by Glück and Baltes (2006), BWP research has previously found that the expression of wisdom-related performance could be enhanced by relatively simple social interventions that encouraged "thinking aloud" about fundamental questions of life. These interventions include getting people to imagine themselves travelling on a cloud around the world, as a way of focusing attention on cultural relativism and tolerance (a key criteria): a technique known to increase wisdom-related knowledge (Böhmig-Krumhaar et al., 2002). In another intervention, decision-making performance was significantly improved by getting people to consider the wisdom problem by either discussing it with a curious friend, or conducting an inner dialogue about the problem (with an imagined thinking partner), or by simply thinking about the problem on their own (Staudinger \& Baltes, 1996). Finally, participants were also found to improve their performance on the wisdom problem when given the choice to select an instance in which they believed they had been wise, or were simply instructed to "make a wise choice" (Glück \& Baltes, 2006).

\section{Wisdom as Balance}

According to Sternberg's (1998) balance theory, wisdom is the application of successful intelligence, creativity, and experience as guided by values toward the achievement of a common good (Sternberg, 2004). A common good is achieved by "balancing one's own interests with the interests 
of other people and with larger interests (including the interests of one's family, one's community, one's nation, and even the world), over the short term as well as the long term, through the use of positive ethical values" (Sternberg, 2019a, p. 4). On the other hand, "foolishness" is considered the opposite of wisdom (Sternberg, 2005). Sternberg (2019b) asserts that wisdom should begin in schools and he has demonstrated a curriculum for promoting wisdom in sixthgrade children that may have applicability for coaches. This includes: (1) teaching the usefulness of interdependence, (2) role-modelling wisdom behaviour, (3) reading about wise judgments, (4) recognising and balancing the interests of self, others and institutions, (5) emphasizing the means by which an end is obtained matters, not just the end itself, (6) understanding the roles of adaptation to existing environments, shaping oneself to fit the environment, or selection of a new environment, and how to balance them, (7) encouraging the formation, critique, and integration of their own values in their thinking, (8) encouraging dialectical thinking (i.e., viewing issues from multiple perspectives and arriving at a reasonable reconciliation of them), (9) showing the importance of dialogical thinking (i.e., critically holding and exploring different ideas or points of view), (10) showing how to search for and reach the common good, (11) showing how to monitor one's own life and thought processes, and (12) understanding the importance of inoculating oneself against the pressures of unbalanced self-interest and small-group interest (Sternberg, 2001).

\section{Wisdom as Reasoning}

Grossmann's (2017) model of wise reasoning in everyday life is an adaptation of the Aristotlean notion of practical wisdom (phronesis). It builds on the work of the BWP and is consistent with the balance approach to wisdom. In earlier work, Grossmann et al. (2013) conceptualised wisdom as "a set of reasoning strategies" (p. 945) rather than static knowledge about a particular situation and its solution. They developed six strategies of how subjects might respond to an experimental conflict. These included (1) considering the perspectives of people involved in the conflict; (2) recognizing the likelihood of change; (3) recognising multiple ways in which the conflict might unfold; (4) recognizing uncertainty and the limits of knowledge; (5) recognizing the importance of, and searching for, compromises between opposing viewpoints, and (6) recognising the importance of, and predicting, conflict resolution. To confirm a state-based approach to wise reasoning, Grossmann et al. (2019) showed how wisdom-related characteristics varied more within the same person across different situations (reflecting the distribution of wisdom-related states) than between people (between-person variability reflecting trait-level distribution). 


\section{The Neurobiology of Wisdom}

Wisdom is a multidimensional and adaptive human attribute and the processes of wise decision making are similarly multidimensional. Meeks and Jeste (2009) used brain localization and neuroimaging to explore aspects of wisdom such as prosocial attitudes and behaviours, social decision making, emotional homeostasis, reflection and self-understanding, and tolerance. They discovered a broad range of neuro-correlates and concluded that wisdom may involve an optimal balance between older brain regions such as the amygdala, and newer ones like the prefrontal cortex. They further observed that a third structure - the anterior cingulate - appeared to be responsible for mediating conflicts between these two brain regions. Thomas et al. (2017) applied this neuro-architecture to propose that wisdom was comprised of social advising (knowing how to solve social problems using good general life knowledge); emotional regulation (primarily associated with more positive emotions); prosocial behaviours (an understanding of how others are feeling); selfreflection and insight; tolerance for divergent values (indicating an openness to new information), and decisiveness in the face of ambiguity (which is needed for quick and effective decisions).

\section{A Third System of Thinking}

The dual process theory of decision-making contends that we utilise two systems of thinking. The first is an intuitive-experiential style, which is automatic, effortless, fast and based on immediate 'gut feelings'. This type of thinking is responsive to images, metaphors and narratives, and is essentially preconscious. The second is more an analytical-rational style that is intentional, effortful, logical, reason-oriented, slower and more deliberate. This type of thinking is responsive to abstract symbols, words, and numbers, and experienced actively and consciously (Epstein et al., 1996). These were later popularized by Kahneman (2011) as System 1 (“thinking, fast"), and System 2 ("thinking, slow"). Contrary to philosophical belief in the supremacy of rational and reasoned thought, it appears that most of our decision making happens through unconscious mental processes, more akin to the intuitive-experiential style. Dijksterhuis (2004) argues that this thinking style is actually preferable when it comes to complex decision making.

According to Epstein (2010), neither system is better than the other, and we appear able to move between intuitive and rational processing depending on the context and various cues in the environment. Intuitive kinds of problems (e.g., interpersonal issues) respond best to intuitive thinking, and rational kinds 
of problems (e.g., balancing a budget) respond best to rational thinking. Occasionally we engage both systems within the same problem (Thorsteinson $\&$ Withrow, 2009). Whilst there are neuro-correlates that support the orthogonal operation of System 1 and System 2 thinking (Gronchi \& Giovanelli, 2018), individual differences do exist in the way people process information before making decisions. That is, some are prone to rely more on an intuitive thinking style, while others may favour a more rational thinking style, even for the same problem (Wen et al., 2016).

For Epstein (2010), System 1 has most of the ingredients for making immediate, emotionally-based, right versus wrong decisions. This is supported by Hauser (2006) who argues that moral decision-making is hard-wired for immediate "gut-feeling" choices that seek, among other things, the protection of human life. Moral reasoning is a post-facto rationalisation of why choices are made, so both systems of thinking seem to be involved in moral judgment, but at different times. Denes-Raj and Epstein (1994) show how people easily flip between intuitive and rational processing when faced with conflict. However, Rand and Epstein (2014) argue that life and death decisions involving altruism and sacrifice require quick, intuitive thinking. Wise decision-making seems to involve both System 1 and System 2 thinking working highly collaboratively. System 2 articulates judgments and makes choices even though it mostly rationalises the ideas and feelings generated by System 1. Yet System 2 can also impose more sensible thinking and overrule System 1.

One of Kahneman's (2011) contributions to decision making is to characterize the "personalities" of these two systems of processing such that they can be more consciously and deliberately applied to everyday choices. This requires a kind of meta-understanding. Similarly, the thinking processes of wise decision-making could be a meta-heuristic (Baltes \& Freund, 2003), an "orchestration" of Systems 1 and 2 in a way suggestive of a super-ordinate intelligence factor ' $\mathrm{g}$ '. In everyday situations, it seems most likely that people rely on System 1 thinking because it is automatic, fast, and experience-based. That is, individuals use their gut feel to quickly arrive at a decision that "feels right". As System 2 thinking is logical, rational, and fact-based, individuals need to slow down and analyse information to deduce a solution. In contrast, a System 3 approach would be more considerative way of assessing information and arriving at a decision. It would involve thinking about how to balance a variety of interests in the short and long-term, especially when dealing with complex and poorly defined problems that have multiple, unknown solutions. An example of this would be deciding on a particular career path, accepting the 
death of a loved one, or solving long-lasting conflicts among family members (see Figure 1.)

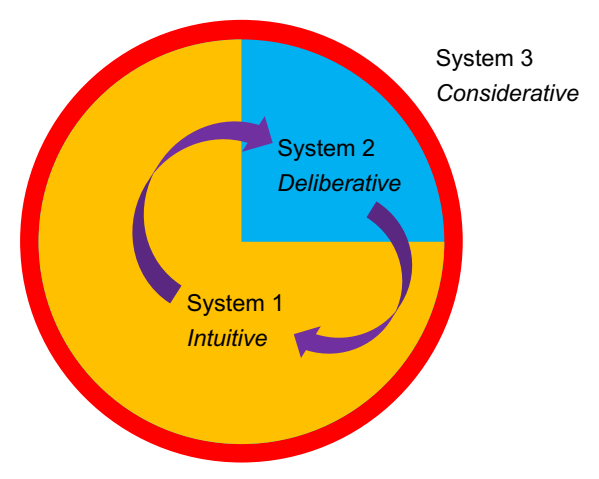

Figure 1. Comparative frequency of system 1, system 2, and system 3 thinking styles

The idea of a third system of processing emerges from the neurobiology of wisdom which proposes that brain structures associated with "balance" are important for wisdom-related performance (Lee and Jeste, 2019). Jeste and Lee (2019) proposed a model of the neurocircuitry of wisdom and its components that posits the prefrontal cortex (along with the anterior cingulate cortex and orbitofrontal cortex) inhibit or modulate brain regions involved in emotional processing and response that facilitate wisdom components. Participants who completed moral reasoning dilemmas while undergoing fMRI, and who showed higher wisdom scores on a psychometric assessment, demonstrated greater engagement of the Default Mode Network (DMN) for moral-personal conditions. Findings such as these suggests the possibility of a third system involvement in the ability to recognise and process social and emotional cues relevant to wise decision making (Thomas et al., 2019). Whilst the DMN is normally associated with "wakeful rest" when daydreaming and "mindwandering", it is now known to contribute to elements of experience that are related to external task performance, such as when an individual is thinking about others, thinking about themselves, remembering the past, and planning for the future (Sormaz et al., 2018). Stark et al. (2018) suggest that the DMN 
may help orchestrate both hedonic (pleasure) and eudaimonic (well-being) brain states.

\section{Assessment Measures}

Whilst the DMN can only be tentatively proposed as the site of System 3 thinking in the brain, the concept is useful to distinguish modes of thinking more aligned with wise reasoning and decision-making than with System 1 and System 2. Fortunately, recent developments in the assessment of wisdom show promise for advancing the concept of a third system (as a coordinator of System 1 and System 2 responses). For example, the Stein Institute for Research on Ageing at the University of California San Diego developed the San Diego Wisdom Scale (SD-WISE), which measures wisdom across six dimensions including social advising, emotion regulation, pro-social behaviours, insight, tolerance for divergent values, and decisiveness (Thomas et al., 2017). In addition, researchers from the BWP group have also developed the Brief Wisdom Screening Scale (BWSS), which expands the original five criteria via the addition of self-transcendence, mindfulness, and compassion (Glück et al., 2013). Finally, Brienza et. al. (2017) have recently developed the four-factor Situated Wise Reasoning Scale (SWIS), which assesses dimensions such as weigh-up uncertainty and change; intellectual humility; search for integration and compromise; and engage others' perspectives.

Taken together, these three scales constitute a way of measuring wisdomrelated knowledge and, potentially, a new domain of information processing that is activated in the presence of doubt, dilemma, or disruption; System 3 thinking. Webb (2018) reports on the early development of a self-assessment scale that combines items from the SD-WISE, the BWSS and the SWIS. Whilst findings from a factor analysis are yet to be published, six dimensions appear to be emerging. These include: focus (items relating to task attention); life experience (items from self-transcendence and openness to new experience); decisiveness (items about readiness to make decisions and readiness to give advice); compassion (items from self-compassion and insight); emotional regulation (items about controlling emotions as well as peace of mind), and; tolerance for divergent values (items connected with accepting others' morals and values, insight into the reasons for one's actions, and openness to diverse viewpoints). Whilst these factors need to undergo further empirical scrutiny, these six dimensions may form the basis of a practice of coaching for wisdom which deliberately enhances the expression of wisdom-related knowledge, thinking, deciding, and acting. 


\section{A Practical Model of Coaching for Wisdom}

The concept of System 3 thinking provides coaches with specific vectors for enhancing wise decision-making, through targeted dialogue, questions, and practice. As such, coaches can aim to facilitate wisdom-related knowledge, performance and decision-making through the use of evidence-based approaches suggested earlier in this paper, along with finding ways to activate the six dimensions of System 3 thinking proposed in this paper:

Focus. Hougaard and Carter (2018) highlight the debilitating effects of distraction on decision making effectiveness. System 3 thinking requires sustained, focused attention on meaningful tasks and activities, balancing mental activity with mental control. Cultivating the ability to focus in the midst of noise has been found to enhance productivity and minimize stress (Webb \& Lee-Bates, 2015), and mindfulness meditation is viewed as a pathway to wisdom (Karunamuni \& Weerasekera, 2019). Coaches can introduce mindfulness practice to improve this dimension.

Life Experience. Life experience is a necessary but not a sufficient condition for System 3 thinking (Baltes \& Staudinger, 2000). However, wisdom offers protection in adverse times (Ardelt \& Jeste, 2018) and wise persons are more likely to reflect on their own life lessons and the lives of others to make sense of what it means to live a good life, and to offer practical and nonjudgmental advice to others (Ardelt, 2005). Coaches, drawing from the field of positive psychology, may demonstrate ways in which the client can curate memories and appreciate the course of their own life as a useful guide to what it means to live a flourishing life (Keyes \& Haidt, 2003).

Decisiveness. An important capability of System 3 thinking is having the paradoxical ability to acknowledge uncertainty and ambiguity whilst managing to make quick and effective decisions. Under complex conditions decisionmaking is a series of experiments with iterative learning potential. Coaches can help build this competency in clients through fostering the techniques of a growth mindset to speed up decisiveness (Dweck, 2006), while at the same time balancing decision speed with a recognition of the "mind traps" that often befall people (Garvey Berger, 2019).

Compassion. Compassion is the feeling that arises when confronted with another's suffering and at the same time motivation to relieve that suffering. It is the capacity to face the collective problems of humanity (or oneself) and strive to do whatever is possible to help. Coaches can encourage self- 
compassion (Pommier, 2011; Neff, 2015), or suggest training exercises as a means of fostering compassion (Weng et al., 2013).

Emotion Regulation. A critical capability of System 3 thinking is to recognize feelings, yet not be overwhelmed by them. Control over emotions is not the same as the absence of emotions but, rather, having control over the intensity and variation in them. David (2016) distinguishes between emotional rigidity (getting hooked by negative thoughts, feelings and behaviours) and emotional flexibility (being flexible with thoughts and feelings), as a means of responding optimally to everyday situations.

Tolerance for Divergent Values. Petersen and Seligman (2004) founded the Values in Action Institute after classifying 24 character strengths and six virtues that are likely to ground day-to-day behaviour. Acceptance of the diversity in strengths offers an opportunity to understand why someone else might rely on strengths that are different to one's own. The key to System 3 thinking appears to be having strong values 'weakly held', which means being more prepared to change one's mind if new information presents itself.

\section{Conclusions}

If we are to encourage the emergence of wisdom in leaders, we need coaches who can practically and skilfully reinforce these principles through making a leader's implicit wisdom resources more explicit (Webb, 2008). This paper draws attention to an evidence-base that can inform the practice of coaching for wisdom, and six dimensions that seem important in there deliberate facilitation; (i) focus, (ii) life experience, (iii) decisiveness, (iv) compassion, (v) emotional regulation, and (vi) tolerance for divergent values. Coaches, who are themselves well advanced in their own development of wisdom-related knowledge, are well-placed to guide their clients towards a sustained practice of wise decision making.

\section{References}

Ardelt, M. (2003). Empirical assessment of a three-dimensional wisdom scale. Research on Aging, 25, 275-324.

Ardelt, M. (2004). Wisdom as expert knowledge system: A critical review of a contemporary operationalization of an ancient concept. Human Development, 47(5), 257-285. 
Ardelt, M. (2005). How wise people cope with crises and obstacles in life. ReVision, 28(1), 7-19.

Ardelt, M. \& Jeste, D.V. (2018). Wisdom and hard times: The ameliorating effect of wisdom on the negative association between adverse life events and well-being. The Journals of Gerontology Series B: Psychological Sciences and Social Sciences, 73(8), 1374-1383.

Baltes, P.B. \& Freund, A.M. (2003). The intermarriage of wisdom and selective optimisation with compensation: Two metaheuristics guiding the conduct of life. In C. Keyes \& J. Haidt (eds.). Flourishing: Positive Psychology and the Life Well-Lived. American Psychological Association.

Baltes, P.B. \& Smith, J. (1990). Toward a psychology of wisdom and its ontogenesis. In R.J. Sternberg (ed.) Wisdom: Its Nature, Origins, and Development. Cambridge University Press.

Baltes, P.B. \& Staudinger, U. (2000). Wisdom: A metaheuristic to orchestrate mind and virtue toward excellence. American Psychologist, 55(1), 122-136.

Birren, J.E. \& Fisher, L.M. (2005). The elements of wisdom: overview and integration. In: R.J. Sternberg \& J. Jordan (Eds.) A Handbook of Wisdom: Psychological Perspectives. New York, NY: Cambridge University Press.

Böhmig-Krumhaar, S.A., Staudinger U.M., \& Baltes, P.B. (2002). In search of more tolerance: Testing the facilitative effect of a knowledge-activating mnemonic strategy on value relativism. Journal of Developmental Psychology and Educational Psychology, 34, 30-43.

Brienza, J.P., Kung, F.Y.H., Santos, H.C., Bobocel, D.R., Grossmann, I. (2017). Wisdom, bias, and balance: Toward a process-sensitive measurement of wisdom-related cognition. Journal of Personality and Social Psychology, 115(6), 1093-1126.

David, S. (2016). Emotional Agility. Penguin Books.

Denes-Raj, V. \& Epstein, S. (1994). Conflict between intuitive and rational processing: When people behave against their better judgment. Journal of Personality and Social Psychology, 66(5), 819-829. 
Dijksterhuis, A. (2004). Think different: The merits of unconscious thought in preference development and decision making. Journal of Personality and Social Psychology, 87, 586-598.

Dweck, C.S. (2006). Mindset. Constable and Robins.

Epstein, S. (2010). Demystifying intuition: What it is, what it does, and how it does it. Psychological Inquiry, 21, 295-312.

Epstein, S., Pacini, R., Denes-Raj, V. \& Heier, H. (1996). Individual differences in intuitive-experiential and analytical-rational thinking styles. Journal of Personality and Social Psychology, 71(2), 390-405.

Garvey Berger, J. (2019). Unlocking Leadership Mindtraps. Stanford University Press.

Glück, J. \& Baltes, P.B. (2006). Using the concept of wisdom to enhance the expression of wisdom knowledge: Not the philosopher's dream but differential effects of developmental preparedeness. Psychology and Aging, 21(4), 679-690.

Glück, J., König, S., Naschenweng, K., Redzanowski, U., Dorner, L., Straßer, I., Wiedermann, W. (2013). How to measure wisdom: content, reliability, and validity of five measures. Frontiers in Psychology, 4, 405.

Gronchi, G. \& Giovanelli, F. (2018). Dual process theory of thought and default mode network: A possible neural foundation of fast thinking. Frontiers in Psychology, 9(1237): 1-4.

Grossmann, I. (2017). Wisdom and how to cultivate it: Review of emerging evidence for a constructivist model of wise thinking. European Psychologist, 22(4), 233-246.

Grossmann, I., Kung, F.Y.H. \& Santos, H.C. (2019). Wisdom as State versus Trait. In: R.J. Sternberg \& J. Glück (Eds.) The Cambridge Handbook of Wisdom. Cambridge University Press.

Grossmann, I., Na, J., Varnum, M.E.W., Kitayama, S. \& Nisbett, R.E. (2013). A route to well-being: Intelligence vs. wise reasoning. Journal of Experimental Psychology: General, 142(3), 944-953. 
Hauser, M.D. (2006). Moral Minds: How Nature Designed Our Universal Sense of Right and Wrong. HarperCollins.

Hougaard, R. \& Carter, J. (2018). The Mind of the Leader: How to Lead Yourself, Your People, and Your Organization for Extraordinary Results. Harvard Business School Publishing.

Intezari, A. \& Puleen, D.J. (2013). Students of wisdom: An integral metacompetencies theory of practical wisdom. In: W.M. Küpers \& D.J. Puleen (eds.). A Handbook of Practical Wisdom: Leadership, Organization and Integral Business Practice. Gower Publishing.

Intezari, A. \& Puleen, D.J. (2019). Wisdom, Analytics and Wicked Problems. Routledge.

Jeste, D.V. \& Lee, E.E. (2019). The emerging empirical science of wisdom: definition, measurement, neurobiology, longevity, and interventions. Harvard Review of Psychiatry, 27(3), 127-140.

Kahneman, D. (2011). Thinking, Fast and Slow. Farrar, Straus and Giroux.

Karunamuni, N. \& Weerasekera, R. (2019). Theoretical foundations to guide mindfulness meditation: A path to wisdom. Current Psychology, 38, 627646.

Keyes, C.L.M. \& Haidt, J. (2003). Human flourishing: The study of that which makes life worthwhile. In: C.L.M. Keyes \& J. Haidt (eds.). Flourishing: Positive Psychology and the Life Well-Lived. American Psychological Association.

Kilburg, R.R. (2000). Executive Coaching: Developing Managerial Wisdom in a World of Chaos. American Psychological Association.

Kilburg, R.R. (2006). Executive Wisdom: Coaching and the Emergence of Virtuous Leaders. American Psychological Association.

Kunzmann, U. \& Baltes, P. (2005). The psychology of wisdom: Theoretical and empirical challenges. In R.J. Sternberg \& J. Jordan (eds.) A Handbook of Wisdom: Psychological Perspectives. Cambridge University Press. 
Lee, E.E. \& Jeste, D.V. (2019). Neurobiology of Wisdom. In R.J. Sternberg, J. \& Glück (Eds.) The Cambridge Handbook of Wisdom. Cambridge University Press.

McKenna, B., Rooney, D. \& Liesch, P.W. (2006). Beyond knowledge to wisdom in international business strategy. Prometheus, 24(3), 283-300.

Meeks, T.W. \& Jeste, D.V. (2009). Neurobiology of wisdom: A literature overview, Archives of General Psychiatry, 66(4), 355-365.

Neff, K.D. (2015). The self-compassion scale is a valid and theoretically coherent measure of self-compassion. Mindfulness, 7(4), 1009-1020.

Nonaka, I. \& Takeuchi, H. (2011). The wise leader: How CEOs can learn practical wisdom to help them do what's right for their companies - and society. The Harvard Business Review, May.

Peterson, C. \& Seligman, M.E.P. (2004). Character Strengths and Virtues: A Handbook and Classification. Oxford University Press.

Pommier, E.A. (2011). The Compassion Scale. Dissertation Abstracts International Section A: Humanities and Social Sciences, 72, 1174.

Rand, D.G. \& Epstein, Z.G. (2014). Risking your life without a second thought: Intuitive decision-making and extreme altruism. Plos One, 9(10),1-6.

Sormaz, M., Murphy, C., Wang, H-T., Hymers, M., Karapanagiotidis, T., Poerio, G., Margulies, D.S., Jefferies, E. \& Smallwood, J. (2018). Default mode network can support the level of detail in experience during active task states. Proceedings of the National Academy of Sciences, 115(37), 9318-9323.

Stark, E.A., Vuust, P. \& Kringelbach, M.L. (2018). Music, dance, and other art forms: new insights into the links between hedonia (pleasure) and eudaimonia (well-being). Progress in Brain Research, 237, 129-152.

Staudinger, U.M. \& Baltes, P.B. (1996). Interactive minds: A facilitative setting for wisdom-related performance? Journal of Personality and Social Psychology, 71(4), 746-762.

Sternberg, R.J. (1998). A balance theory of wisdom. Review of General Psychology, 2, 347-365. 
Sternberg, R.J. (2001). Why schools should teach for wisdom: The balance theory of wisdom in educational settings. Educational Psychologist, 36(4), 227-245.

Sternberg, R.J. (2004). What is wisdom and how can we develop it? The Annals of the American Academy of Political and Social Science, 591,164-174.

Sternberg, R.J. (2005). Foolishness. In: R.J. Sternberg \& J. Jordan (eds.), $A$ Handbook of Wisdom: Psychological Perspectives. Cambridge University Press.

Sternberg, R.J. (2019a). Race to samara: The critical importance of wisdom in the world today. In R.J. Sternberg \& J. Glück (eds.) The Cambridge Handbook of Wisdom. Cambridge University Press.

Sternberg, R.J. (2019b). Where have all the flowers gone? An analysis of teaching for wisdom over the years. In R.J. Sternberg, H.C. Nusbaum, and J. Glück (Eds.) Applying Wisdom to Contemporary World Problems. Palgrave Macmillan.

Thomas, M.L., Bangen, K.J., Palmer, B.W., Martin, A.S., Avanzino, J.A., Depp, C.A., Glorioso, D., Daly, R. \& Jeste, D.V. (2017). A new scale for assessing wisdom based on common domains and a neurobiological model: The San Diego Wisdom Scale (SD-WISE). Journal of Psychiatric Research, 108, 40-47.

Thomas, M.L., Martin, A.S., Eyler, L., Lee, E.E., Macagno, E., Devereaux, M., Chiong, W., Jeste, D.V. (2019). Individual differences in level of wisdom are associated with brain activation during a moral decision-making task. Brain Behavior, 6(9), e01302.

Thorsteinson, T.J. \& Withrow, S. (2009). Does unconscious thought outperform conscious thought on complex decisions? A further examination. Judgment and Decision Making, 4(3), 235-247.

Webb, P.J. (2008). Coaching for wisdom: Enabling wise decisions. In D.B. Drake, K. Gørtz, \& D. Brennan (eds.) The Philosophy and Practice of Coaching. Jossey-Bass.

Webb, P.J. (2018). Coaching for wisdom. In K. Brush, \& I. Sobolewska (eds.) $8^{\text {th }}$ EMCC International Mentoring, Coaching, and Supervision Research 
Conference (pp. 220-231), European Coaching and Mentoring Council, Brussels, Belgium.

Webb, P.J. \& Lee-Bates, B. (2015). Effects of mindfulness training on workplace performance. Proceedings of the $11^{\text {th }}$ Industrial and Organisational Psychology Conference, Australian Psychological Society, Melbourne, Australia.

Wen, S.W., Ryan, P. \& Ryan, C.A. (2016). Systems 1 and 2 thinking processes and cognitive reflection testing in medical students. Canadian Medical Education Journal, 7(2): e97-e103.

Weng, H.Y., Fox, A.S., Shackman, A.J., Stodola, D.E., Caldwell, J.Z.K., Olson, M.C., Rogers, G.M. \& Davidson, R.J. (2013). Compassion training alters altruism and neural responses to suffering. Psychological Science, 24(7), 1171-1180.

\title{
Acknowledgements
}

With grateful acknowledgement to Dr Barry Partridge, Adjunct Professor at Torrens University Australia for his partnership on the design and validation of the DPS (Decision Processing Survey), and to Ethan Sagan-Chang, Department of Psychology at the University of Essex, for his statistical validation of the T3 (Third System of Thinking) Profile.

\author{
Author Contact \\ Peter J. Webb \\ Intentional Training Concepts Pty Ltd \\ Melbourne, VIC \\ Australia \\ E: peter_webb@intentional.com.au
}

